\title{
Barrett's esophagus and esophageal cancer: An overview
}

\author{
VINCENZA CONTEDUCA ${ }^{1}$, DOMENICO SANSONNO ${ }^{1}$, GIUSEPPE INGRAVALLO ${ }^{2}$, STEFANIA MARANGI $^{3}$, \\ SABINO RUSSI $^{1}$, GIANFRANCO LAULETTA ${ }^{1}$ and FRANCO DAMMACCO ${ }^{1}$ \\ Departments of ${ }^{1}$ Internal Medicine and Clinical Oncology and ${ }^{2}$ Pathology, University of Bari Medical School, Bari; \\ ${ }^{3}$ Digestive Endoscopy Unit, Department of Oncology, John Paul II Center for High Technology Research \\ and Education in Biomedical Sciences, Campobasso, Italy
}

Received March 15, 2012; Accepted April 23, 2012

DOI: 10.3892/ijo.2012.1481

\begin{abstract}
Although esophageal cancer (EC) is the eighth most common cancer in several European countries, it is one of deadliest worldwide. The most frequent predisposing factor implicated in its development is Barrett's esophagus (BE), an acquired metaplastic transformation of the esophageal lining cells from normal squamous epithelium into specialised or intestinal-like columnar epithelium. The major risk factor for $\mathrm{BE}$ is gastroesophageal reflux disease. Although BE is in itself a benign and often asymptomatic disorder, its clinical importance stems from the recognition that it represents the main precursor lesion for the development of esophageal adenocarcinoma (AC), a tumor that is rapidly increasing especially in developed countries and is associated with a low survival rate. This paper provides an overview of the epidemiology and natural history of $\mathrm{BE}$ as well as of the possible pathogenetic mechanisms underlying the development of $\mathrm{BE}$ and its progressive transition to AC. New diagnostic tests are described, recommendations for screening and surveillance are provided and surgical and abla-
\end{abstract}

Correspondence to: Dr Vincenza Conteduca, Liver Unit, Department of Internal Medicine and Clinical Oncology, University of Bari Medical School, Piazza G. Cesare 11, I-70124 Bari, Italy

E-mail: cinzia.conteduca@libero.it

Abbreviations: AC, adenocarcinoma; BE, Barrett's esophagus; BMP4, bone morphogenetic protein 4; $\mathrm{CGH}$, comparative genomic hybridization; COX-2: cyclo-oxygenase-2; EC, esophageal cancer; GER, gastro-esophageal reflux; GERD, gastro-esophageal reflux disease; H. pylori, Helicobacter pylori; IGF-1, insulin-like-growth factor-1; LOH, loss of heterozygosity; NBI, Narrow Band Imaging; $\mathrm{NF}-\kappa \mathrm{B}$, nuclear factor- $\kappa \mathrm{B}$; NSAIDs, non-steroidal anti-inflammatory drugs; PPIs, proton-pump inhibitors; SCC, squamous cell carcinoma; SIM, specialized intestinal metaplasia; STAT3, signal transducer and activator of transcription 3 ; TGF- $\beta$, transforming growth factor $\beta$

Key words: adenocarcinoma, Barrett's esophagus, biomarkers, esophageal cancer, gastro-esophageal reflux disease, proton pump inhibitors, squamous cell carcinoma tive procedures to treat dysplastic lesions and early neoplasia are discussed. Claimed chemopreventive agents and biomarkers that in the near future may help identify people with a higher risk of EC are also considered.

\section{Contents}

1. Introduction

2. Epidemiology

3. Natural history

4. Pathogenetic mechanism(s), genetic and epigenetic factors

5. Clinical features

6. Diagnosis, screening and surveillance

7. Treatment

\section{Introduction}

Esophageal cancer (EC) is an important worldwide health problem because of its poor prognosis and a relatively high incidence in some parts of the world. Advances in surgical techniques, chemotherapy and radiotherapy have not substantially modified its prognosis over the last 25 years. The large majority of esophageal tumors are accounted for by squamous cell carcinomas (SCCs: 60-70\%) or adenocarcinomas (ACs: 20-30\%), whereas melanomas, leiomyosarcomas, carcinoids and lymphomas are rarely diagnosed (1).

SCC occurs most often in patients with histories of tobacco consumption or ethanol intake. Additional risk factors include prior caustic ingestion, chronic achalasia, and non-epidermolytic palmo-plantar keratoderma (tylosis), a rare autosomal dominant disorder associated with genetic abnormalities at chromosome 17q25, hyperkeratosis of the palms and soles, and thickening of oral mucosa. Plummer-Vinson syndrome, characterized by dysphagia, iron-deficiency anemia and esophageal webs, is another risk condition for SCC. Previous radiotherapy to the mediastinum, for example in patients with breast cancer and lymphoma, is also linked to the development of EC, usually 10 or more years after exposure to radiation (1).

Esophageal AC, on the other hand, can complicate longstanding acid reflux, and the main condition predisposing to its 
onset is Barrett's esophagus (BE), an acquired disorder whose prevalence is rapidly increasing worldwide. The aim of this review is to provide an update of the epidemiology, clinical features, pathogenetic mechanisms and new diagnostic and therapeutic approaches to $\mathrm{BE}$ and $\mathrm{EC}$.

\section{Epidemiology}

EC is the eighth most common malignant tumor worldwide. In 2010 an estimated 16,640 new cases and 14,500 deaths due to EC occurred in the United States (2). It is associated with a 5 -year survival rate of 15 to $20 \%$. The lifetime risk of developing this cancer is $0.8 \%$ for men and $0.3 \%$ for women. The risk increases with age and the mean age at diagnosis is 67 years. Although its incidence is largely variable among different geographical areas, it is endemic in many parts of the world, particularly in Asia, Southern and Eastern Africa (3). The area with the highest reported incidence of EC is the so-called Asian 'esophageal cancer belt', which stretches from eastern Turkey through north-eastern Iran, northern Afghanistan and southern Russia to northern China (4).

Approximately $75 \%$ of all ACs are localized in the distal tract of esophagus, whereas SCCs are usually distributed between the middle and lower third. SCC is more common in the endemic areas of the world. On the contrary, AC is more frequent in regions such as North America and Western Europe. Although SCC is the most common histotype, over the past three decades a slight decline in its prevalence and, conversely, a dramatic increase in the prevalence of AC have been recorded, especially in the United States, United Kingdom and Western Europe (4,5). Any factor that causes chronic inflammation of the esophageal mucosa, especially alcohol intake in combination with smoking, may increase the risk of esophageal SCC (2).

Patients with BE have a 30 to 40 times higher risk of developing EC. In the United States, approximately 1.5-2 million people are affected with $\mathrm{BE}$, and its prevalence in people without symptoms of gastro-esophageal reflux (GER) is about $0.4-6 \%$ (6). Additional information has been provided by the Kalixanda and SILC studies $(7,8)$ that involved about 1,000 volunteers, a representative sample of local residents who underwent endoscopy. The Kalixanda study, performed in Northern Sweden, showed that $10.3 \%$ of them had columnarlined esophagus on endoscopic examination, and $1.6 \%$ had histologically confirmed BE. In the SILC study, performed in Shanghai, endoscopically suspected BE was present in $1.9 \%$ of the subjects examined, $26 \%$ of whom having an extent of metaplasia $\geq 3 \mathrm{~cm}$.

The risk of malignant progression has been examined in over 8,500 patients with BE using the Northern Ireland BE Register and followed-up for a mean of 7 years (9). Incidence of EC or gastric cardia cancer or high-grade dysplasia combined was found to be $0.22 \%$ per year. In patients with specialized intestinal metaplasia (SIM), the combined incidence was $0.38 \%$ per year. A statistically significant elevation of cancer risk was observed in patients with vs. those without SIM at index biopsy $(0.30 \%$ per year vs. $0.07 \%$ per year), in men compared with women $(0.28 \%$ per year vs. $0.13 \%$ per year $)$ and in patients with low-grade dysplasia compared with those lacking dysplasia ( $1.4 \%$ per year vs. $0.17 \%$ per year). Moreover, in a nationwide, population-based, cohort study (10) that included all patients with BE collected in Denmark in the period 1992 through 2009, the relative risk of $\mathrm{AC}$ among patients with $\mathrm{BE}$, compared with the risk in the general population, was 11.3 and the annual risk of esophageal AC was $0.12 \%$. Low-grade dysplasia on the index endoscopy was associated with an incidence rate for AC of 5.1 cases per 1,000 person-years, whereas the incidence rate for patients without dysplasia was 1.0 case per 1,000 person-years. These two large population-based studies indicate that $\mathrm{BE}$ remains a strong risk factor for esophageal $\mathrm{AC}$, but the absolute annual risk is remarkably lower than the previously assumed risk of $0.5 \%$ (11) and suggest that current surveillance guidelines should be revised $(9,10,12)$.

A major risk factor for $\mathrm{BE}$ is gastro-esophageal reflux disease (GERD), whose prevalence, defined as at least weekly heartburn and/or acid regurgitation, is estimated to be $10-20 \%$ in the Western world (13). However, only $10-15 \%$ of patients with chronic GERD develop BE, indicating that additional genetic and/or environmental factors are likely to be involved. Other risk factors associated with the development of esophageal AC include advanced age, male gender, white race and elevated body mass index. GERD is associated with obesity, that increases intra-abdominal pressure and may favor reflux (14). Notably, an inverse association has been described between the presence of $\mathrm{BE}$ and $H$. pylori infection, probably linked to the reduction in acid reflux associated with gastric atrophy (15).

\section{Natural history}

The metaplastic transformation of the normal squamous epithelium lining the esophageal mucosa into a differentiated epithelium with crypt architecture that resembles the intestinal columnar epithelium was first described by Norman Barrett in 1950 (16), correlated with GERD in 1953 (17) and linked to esophageal AC in 1975 (18). On the basis of meta-analysis assessment, the incidence of esophageal AC among individuals with $\mathrm{BE}$ has been reported to be about $0.5 \%$ per patient-year (11) although, as already mentioned, a much lower absolute annual risk $(0.12 \%)$ has been calculated in a recent cohort study (10). Esophageal AC is an uncommon cause of death in people with $\mathrm{BE}$ and, therefore, the majority of patients affected with this last condition die with their disease, not because of it.

Neoplastic transformation of BE is a stepwise process that includes non-dysplastic disease, low-grade dysplasia, high-grade dysplasia and $\mathrm{AC}$, although patients with $\mathrm{BE}$ under endoscopic surveillance often develop cancer without prior biopsy detection of each of these stages (Fig. 1). In 2000, the World Health Organization International Agency, according to Vienna classification system, changed the term 'dysplasia' into 'intraepithelial' or 'noninvasive' neoplasia, a definition that more appropriately identifies a neoplastic lesion in its early pre-invasive stage $(19,20)$.

\section{Pathogenetic mechanism(s), genetic and epigenetic factors}

$\mathrm{BE}$ is considered an acquired pre-malignant lesion of the gastrointestinal tract, but there are still major gaps in the understanding of pathogenetic factors that lead to its development and trigger progression to dysplasia and esophageal AC (Fig. 2). Since only $10-15 \%$ of patients with GER will eventually develop BE, additional factors capable of inducing its onset may be inferred. The risk of both $\mathrm{BE}$ and esophageal $\mathrm{AC}$ has long been related 


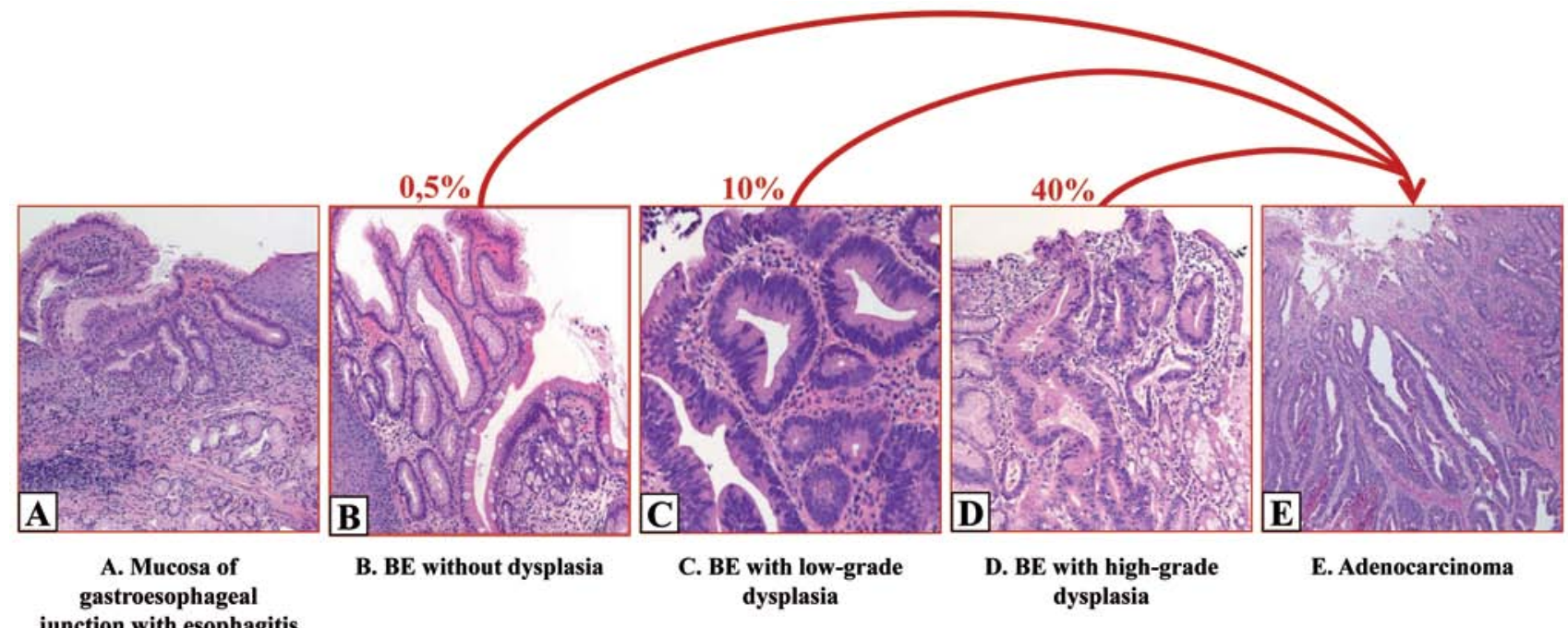

Figure 1. Histopathologic features of the natural history of Barrett's esophagus (BE). Progressive transition from squamous epithelium to intestinal metaplasia, dysplasia and adenocarcinoma (AC). Panel A, normal stratified squamous epithelium. Panel B, BE without dysplasia, with the presence of goblet cells. Panel C: BE with low-grade dysplasia. Panel D: BE with high-grade dysplasia. Panel E: AC.

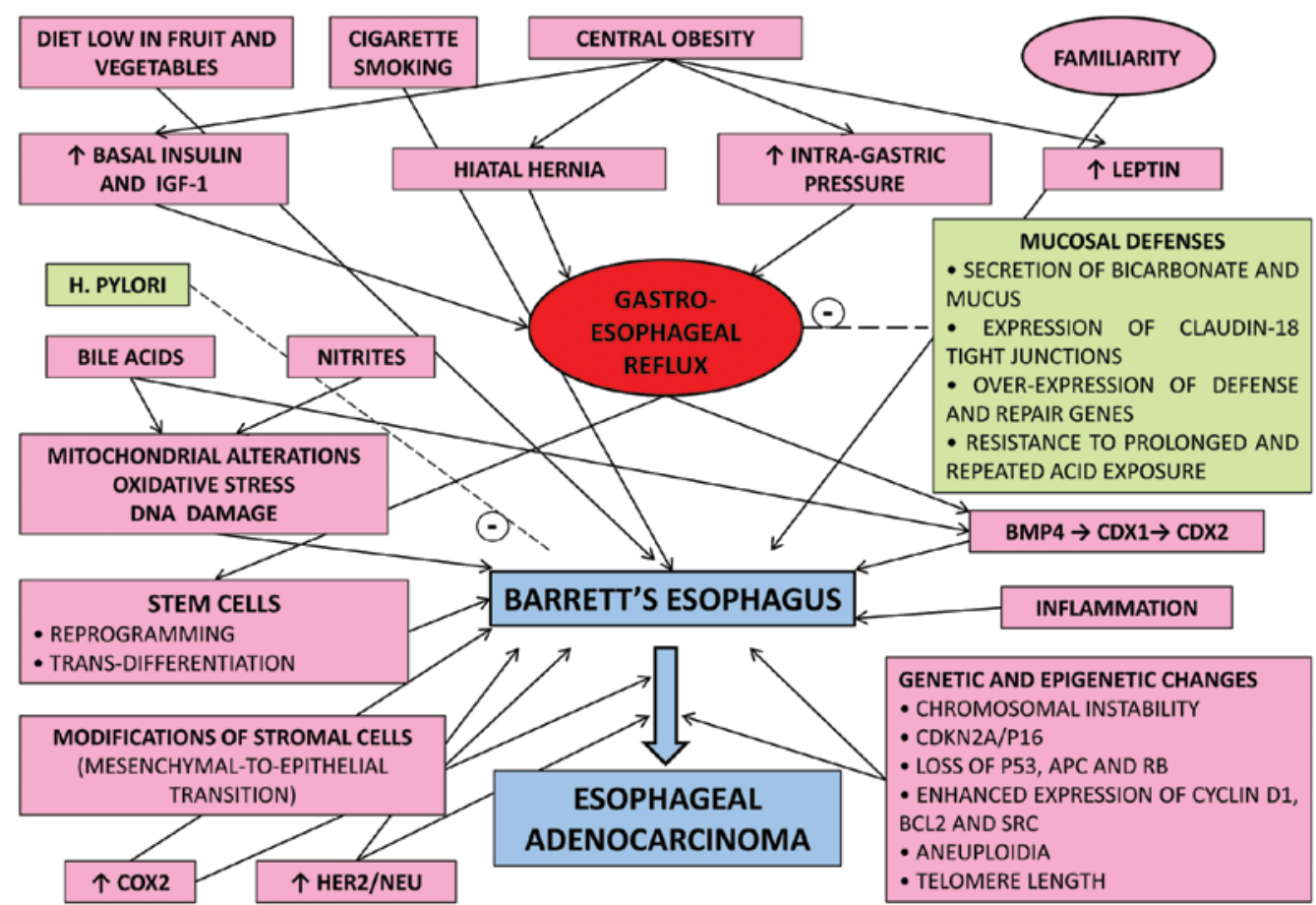

Figure 2. Hypothetical representation of risk factors and pathways for the development of Barrett's esophagus and esophageal adenocarcinoma. Gastro-esophageal reflux plays a central role in the pathogenesis of $\mathrm{BE}$ and several factors are thought to contribute to its occurrence, including central obesity, which causes hiatal hernia, increased intragastric pressure, high levels of insulin and IGF-1 and leptin elevation. Additional risk factors are diet low in fruit and vegetables, cigarette smoking, elevated levels of nitrites and bile acids. Familiarity may be an important predisposing factor to the development of BE and eventually oesophageal adenocarcinoma. Genetic and epigenetic studies have shown modifications of intestinal-specific transcription factors (CDX1 and CDX2) and protein (BMP4), that regulate the development and differentiation of the intestinal columnar epithelium. Overexpression of COX2 and HER2/neu have also been claimed to lead to the development of BE. Reprogramming and/or trans-differentation of stem cells situated in the basal layer of the normal squamous epithelium, as well as modifications of stromal cells characterized by mesenchimal-to-epithelial transition, are presently the object of intense investigation for their presumed role in the pathogenesis of BE. In contrast to the mentioned enhancing factors, $H$. pylori infection and gastro-oesophageal mucosal defenses (dotted arrows) exert a protective role against the formation of $\mathrm{BE}$.

to body-mass index. However, the association between bodymass index and BE has been recently shown to be relatively low, whereas central adiposity does indeed represent a significant risk factor (21).
Patients with central obesity are more predisposed to hiatal hernia and present an increased intra-gastric pressure that enhances reflux. In addition, they usually have higher basal insulin and insulin-like-growth factor-1 (IGF-1) levels, which 
promote cell proliferation and determine cell differentiation. Three IGF-1 gene polymorphisms have been shown to be associated with esophageal AC or its precursors, and can be considered as risk markers (22). Moreover, these patients exhibit higher serum levels of leptin, a hormone secreted by visceral fat that possibly promotes carcinogenesis by mitogenic and angiogenic means (23). On the other hand, in a cross-sectional study increased levels of low molecular weight adiponectin were associated with a decreased risk of BE among patients with GERD (24).

Esophageal mucosal injury from acid reflux is considered a prerequisite for the development of $\mathrm{BE}$ although, as already stated, additional factors besides acid reflux are likely responsible for the development of intestinal metaplasia. The distal esophagus is chronically exposed to acid reflux even in healthy volunteers, with no evidence of esophagitis or metaplasia (25). Whether the esophageal mucosa in patients with $\mathrm{BE}$ has a higher permeability to physiologic amounts of acid is still unclear. In an experimental study carried out in mice (26), acute stress was found to increase esophageal mucosa permeability by itself. Thus, there is a connection between stress and exposure of the esophageal mucosa to acid pepsin, leading to increased permeability and dilated intercellular spaces. Probably, intestinal metaplasia develops as a protective mechanism against chronic acid reflux at the molecular level. Several mucosal defenses have been identified, including the secretion of bicarbonate and mucus, expression of claudin-18 tight junctions, over-expression of defense and repair genes, and resistance to prolonged and repeated acid exposure (27).

Elevated concentrations of nitric oxide, that are potentially mutagenic, are detected at the gastro-esophageal junction in this acidic microenvironment. Nitrites are present in the saliva and derive from reduction of dietary nitrates effected by oral bacteria. Nitrites are reduced into nitric oxide by gastric juice with higher concentrations in correspondence of the gastro-esophageal junction and gastric cardias, thus inducing a potentially increased risk of metaplasia and carcinogenesis. Nitric oxide has also been shown to induce DNA double-strand breaks in primary BE cells (28). In addition, different bile acids have been identified in the GER, including glycocholic acid, taurocholic acid, glycodeoxycholic acid and glycochenodeoxycholic acid. Bile acids can cause injury to the esophageal epithelium and lead to the development of metaplasia by inducing mitochondrial alterations, oxidative stress or DNA damage (29).

It is not clearly established whether BE is a hereditary condition. No single causative gene has been identified, although the condition is more prevalent in first-degree relatives of patients with BE. Familiarity can be detected in about $7 \%$ of patients in whom $\mathrm{BE}$ and $\mathrm{AC}$ have been diagnosed, a percentage which is higher than that reported in general population surveys $(30,31)$. Since the heritability is weak and does not correspond to any commonly recognized pattern, the genetic condition underlying $\mathrm{BE}$ is probably a polygenic trait, rather than a single gene mutation. Studies assessing gene expression in BE compared with squamous tissue suggest that different cellular pathways are activated in metaplasia, but the cellular origin of the columnar cells of BE is not yet clear (11).

Formerly Barrett's metaplasia was considered the result of migration of gastric columnar cells to the gastro-esophageal junction (32). It is now widely accepted that columnar cells arise within the esophagus, possibly as the result of a modification in the stem cells responsible for the constant replenishing of the esophageal lining epithelium, such that they are reprogrammed to produce columnar, rather than squamous cells. Stem cells of the esophageal epithelium possibly home in the intra-papillary regions of the basal layer (33), or else reside in the submucosal esophageal glands (34), connected to the surface by a cuboidal cell-lined duct that penetrates the epithelium and opens into the esophageal lumen. It seems reasonable to hypothesize that pluripotent stem cells located distally within the duct lining become exposed following erosive esophagitis consequent to chronic reflux and promote the differentiation into intestinaltype columnar cells that migrate out to repopulate the injured epithelium. Bone marrow-derived stem cells have also been reported to contribute to metaplasia in a rat model of BE (35).

Alternatively, rather than an abnormality of stem cells, the acidic environment determined by chronic GER may induce cellular trans-differentiation through an epigenetic effect on post-mitotic cells. During development, the esophagus is initially lined by a columnar-type epithelium, that is replaced by the mature squamous epithelium during late embryogenesis through trans-differentiation (36). This suggests that columnar cells which characterize Barrett's metaplasia may result from a change in the developmental program. Another possibility is that Barrett's metaplasia arises indirectly as a consequence of mutational and/or environmental modifications in the stromal cells (eg. myofibroblasts, inflammatory cells, etc.) of the submucosa. Cytokines and other regulatory signals from the stromal cells could potentially influence the differentiation and development of cells within the epithelial layer (37). It has also been suggested that the columnar epithelium of BE arises directly from stromal cells via a mesenchymal-to-epithelial transition (38).

The mechanisms directly driving trans-differentiation likely involve important transcriptional regulators such as the homeobox genes, a family of DNA-binding proteins. In a rat model of BE (39), acid reflux induces the sequential expression of CDX1, followed by CDX2, in esophageal epithelial cells. CDX1 and CDX2 are intestinal-specific transcription factors that regulate the development and differentiation of the intestinal columnar epithelium, and are likely to play a role in the development of $\mathrm{BE}$ (40). Neither factor is expressed in the normal esophagus and stomach, whereas both are highly expressed in regions of intestinal metaplasia (41). Strikingly, transgenic expression of CDX2 in the stomach leads to the development of intestinal metaplasia in mice (42), while the loss of CDX2 in intestinal tissue leads to the formation of stratified squamous epithelium similar to that found in the esophagus (43). Furthermore, chronic exposure to acid induces expression of CDX2 in normal mouse esophageal cells. Additional data indicate that epigenetic changes are partly responsible for abnormal genetic expression that might determine the development of BE. For example, demethylation of the promoter regions of CDX2 might allow the expression of this gene in a previously quiescent cell line, inducing intestinal-like differentiation of the progeny cells. Such a mechanism might be a link between genetic factors and environmental exposures. In animal models, epithelial exposure to the duodenal content affects the expression of CDX2 (44).

One of the proteins exclusively expressed in BE epithelium is bone morphogenetic protein 4 (BMP4). It belongs to the transforming growth factor- $\beta$ (TGF- $\beta$ ) family, that seems to be 
involved in controlling cellular differentiation, migration and proliferation. BMP4 and its downstream targets are present in biopsy specimens from BE mucosa. BMP4 is also present in squamous epithelium in the area of esophagitis, but not in normal squamous esophageal mucosa (45). A possible link between CDX2 and BMP4 leading to BE has been proposed. Pro-inflammatory factors, such as acid and bile, lead to upregulation of BMP4 expression in esophageal mesenchyme. In turn, BMP4 activates stem cells in the basal layer of the esophageal epithelium, initiating gene transcription, which leads to the development of columnar epithelium. If CDX2 is activated, the columnar epithelium will be a specialized columnar cell type, whereas lack of activation of CDX2 will lead to a nonspecialized columnar cell type (46). Inflammation, in particular upregulation of IL-6, which activates the signal transducer and activator of transcription 3 (STAT3) pathway, is also important for progression of $\mathrm{BE}$. Bile acids activate the $\mathrm{CDX} 2$ promoter via nuclear factor- $\kappa \mathrm{B}(\mathrm{NF}-\kappa \mathrm{B})$, resulting in the production of intestinal type mucin in esophageal keratinocytes (47).

Genomic instability seems to be a fundamental property of neoplastic progression. Acid and bile in the GER, either directly or indirectly, induce genetic and/or epigenetic changes that lead to the onset of $\mathrm{BE}$ and its progression to esophageal $\mathrm{AC}$. Multiple genetic changes are indeed present in BE. Whole genome studies have demonstrated that the majority of $\mathrm{BE}$ samples show some level of chromosomal instability, including copy number gains, copy number losses and loss of heterozygosity (LOH). Genetic abnormalities increase during different stages of carcinogenesis: from less than $2 \%$ of the genome in early stages Barrett's metaplasia to over $30 \%$ in late stages (48). The most frequent genetic alteration is loss of the short arm of chromosome 9, including 9p21.3 (CDKN2A/p16). In early stage $\mathrm{BE}$, additional abnormalities have been detected, such as copy loss on $3 p$ and 16q. Among genetic alterations usually associated with cancer, loss of p53, APC and RB and overexpression of cyclin D1, Bcl2 and SRC should be mentioned (49).

Flow cytometric, cytogenetic, comparative genomic hybridization (CGH) and other studies have shown that aneuploidy, $\mathrm{LOH}$, and cell cycle alterations are more frequent when grades of dysplasia are higher. Aneuploid cell populations are found in approximately two-thirds of patients with high-grade dysplasia and in about $90 \%$ of those with esophageal AC. Tumor suppressor genes, like other genes, may be inactivated by mutation, $\mathrm{LOH}$, or by epigenetic suppression of gene expression by DNA hypermethylation, which involves the abnormal addition of methyl $(\mathrm{CH} 3)$ groups to cytosine bases at particular sites (CpG dinucleotides) in gene promoter regions (39). The relative risk of developing esophageal AC at 5 years in those with baseline $9 \mathrm{pLOH}$ and $17 \mathrm{pLOH}$ and a DNA content abnormality was $79 \%$, compared to no case of $\mathrm{AC}$ in patients with none of these abnormalities at baseline (50).

In a longitudinal study, baseline analysis of blood samples has revealed that a shorter telomere length was associated with increased risk of progression to esophageal AC (51), and in a case-control study, overall telomere length, as well as $17 \mathrm{p}$ and $12 q$ telomere lengths, but not $11 q$ and $2 p$ telomere lengths, were associated with increased esophageal AC (52). These results suggest that chronic systemic inflammation is important for the development of $\mathrm{BE}$ and esophageal $\mathrm{AC}$, independently of smoking, obesity, and the use of non-steroidal anti-inflammatory drugs (NSAIDs). Therefore, telomere length may be a useful biomarker to stratify risk in people with BE (53).

H. pylori infection represents an important environmental factor that possibly interferes with carcinogenesis in the esophagus. The infection might decrease intra-gastric acidity by generating large amounts of ammonia, or cause severe corpus gastritis with destruction of parietal cells, thereby reducing acid output, or both. Infection with $\mathrm{CagA}^{+}$strains of $H$. pylori is associated with high grades of gastric inflammation and increased propensity to develop gastric atrophy and intestinal metaplasia. Particularly in East Asia, but also in the United States and Europe, H. pylori infection has protective effect from the development of erosive esophagitis and even BE. The decreased prevalence of $H$. pylori infection in developed countries is temporally associated with an increased incidence of gastro-esophageal complications, including BE (54).

There is a tissue overexpression of cyclo-oxygenase-2 (COX-2) in BE and esophageal AC, but it is not known at what stage they may act in the esophageal inflammation-metaplasiaAC sequence. Therefore, the use of aspirin and NSAIDs is probably associated to a reduced risk of BE development (55). Other factors with protective effect are dietary factors, such as high intake of fibers, fruit and vegetables, and meat (56), and nutrients, including high intake of vitamin $\mathrm{C}$, beta-carotene and vitamin E (57).

HER-2/neu oncogene is also overexpressed/amplified in about $15-30 \%$ of patients with BE or esophageal AC. HER2/ neu has a possible role in the early transition from dysplasia to $\mathrm{AC}$ and correlates with a poor prognosis. Thus, it could help to identify patients at high risk of malignant transformation and could be a target for treatment of esophageal premalignant and malignant lesions (58).

\section{Clinical features}

$\mathrm{BE}$ is by itself an asymptomatic disorder, but its clinical presentation is associated with GERD in $10-15 \%$ of cases. The Montreal consensus conference (59) defined GERD as 'a condition which develops when the reflux of gastric contents causes troublesome symptoms and/or complications'. The severity of reflux esophagitis is commonly classified into four grades according to the Los Angeles Classification System (60), depending on the presence, length and circumferential extent of clearly visible breakages on the mucosal surface. Grades A and $\mathrm{B}$ can be considered mild and moderate, respectively; grades $\mathrm{C}$ and $\mathrm{D}$ are severe and associated with a much higher risk of developing major complications such as peptic stricture, deep ulceration and $\mathrm{BE}$.

The patient with BE is typically a middle-aged, overweight, white man; the average age at diagnosis is 55 years. The most common symptoms, which result from abnormal reflux of the acidic gastric content, are heartburn, regurgitation, dyspepsia and epigastric pain. In the Western world heartburn affects up to $40 \%$ of adults, but approximately $20 \%$ of them experience it on a weekly basis. Heartburn occurs in about $70 \%$ of GERD patients and is considered a good marker for the disease, although many patients with biopsy-proven BE report no symptoms (61).

In some patients, GERD may induce chest pain that can mimic angina pectoris. A variety of ear, nose and throat complications can also be associated with GERD, which primarily 
result directly or indirectly from refluxed gastric acid. In addition, hoarseness, chronic cough, globus, pharyngitis, sinusitis, vocal chord granuloma, subglottic stenosis, and even laryngeal cancer are reported with variable frequency. Less commonly associated conditions include asthma, dental erosions due to acid in the mouth, and acid aspiration, which can cause pulmonary damage.

The diagnosis of GERD and BE can be problematic for at least two reasons. First, patients can complain of any or none of a diverse range of esophageal and extra-esophageal symptoms. Second, the severity of symptoms is often unrelated to the severity of the disease, that correlates more often with frequency and chronicity (total number of years with reflux symptoms) of GERD clinical features. The different degrees of dysplasia do not modify clinical presentation of BE patients; therefore, only endoscopy permits to identify various stages in the evolution of BE up to transformation of Barrett's metaplasia into EC. Consequently, the prognosis of $\mathrm{EC}$ is quite poor, because most patients present with advanced disease, whose symptoms can be attributed to the direct effects of the local tumor, regional or distant complications rather than to GERD clinical features (present in only $21 \%$ of EC patients).

Most patients with EC complain of dysphagia (74\%), and odynophagia (17\%) at the time of diagnosis. Weight loss is also common (57\%) and is an independent indicator of a poor prognosis if there is a loss of more than $10 \%$ of body mass. Dyspnea, cough, hoarseness and pain (retrosternal, back or right upper abdominal) occur less often but may reflect the presence of extensive, unresectable disease.

\section{Diagnosis, screening and surveillance}

The diagnosis of BE should meet two criteria $(62,63)$. The first is based on upper endoscopy, that shows the displacement of the squamo-columnar junction. While the intersection of the squamous epithelium of the esophagus and the columnar epithelium of the stomach occurs at the level of the ' $\mathrm{Z}$ line', in BE salmoncolored epithelium projects into the tubular esophagus, such projections appearing as tongues of tissue or as circumferential involvement of the mucosa, or both. The second diagnostic criterion is based on the histopathology of bioptic specimens of the tubular esophagus showing the presence of SIM, with or without goblet cells. At variance from the position of the American Society of Gastroenterology (63), but according to the British Society of Gastroenterology guidelines, the identification of goblet cells in the metaplastic epithelium is not required for diagnosis (64). Provided that biopsy samples derive from endoscopically recognized abnormalities and in spite of interobserver variability, histologic assessment of dysplasia (Fig. 1) remains a crucial and largely irreplaceable method of diagnosis and surveillance (62).

If the histological diagnosis is lacking but the endoscopic picture is suggestive, BE should be more appropriately defined as 'esophageal metaplasia'. There are three main histological subtypes of BE, namely: i) a gastric fundus subtype with parietal and chief cells; ii) a junctional (cardias) subtype with mucus-secreting glands; and iii) a distinctive metaplastic columnar epithelium with intestinal-type goblet cells. These subtypes occupy different zones of the esophagus, in that the intestinal-type metaplasia with goblet cells is found most proxi- mally to the squamous epithelium, followed by the junctional (cardias) subtype in the middle, and the gastric fundus subtype most distally. Histological subgroupings of $\mathrm{BE}$ are associated with a different capability to develop malignancy. The fundic subtype implies a very low risk of developing esophageal AC, whereas the metaplastic columnar epithelium with intestinaltype goblet cells and the junctional (cardias) type have a more significant risk of malignant transformation (62). BE can also be classified as short-segment disease $(<3 \mathrm{~cm})$ or long-segment disease $(\geq 3 \mathrm{~cm})$ in relation to the length of the metaplastic epithelium on endoscopic examination. Short segments are not considered clinically relevant, even if the risk of developing cancer is increased as compared with the general population. More recently, BE has been defined as 'salmon-colored mucosa of any length in an esophagus harboring goblet cells' $(64,65)$.

Endoscopy remains a constant requirement for the routine diagnosis of esophageal columnar metaplasia. The main objectives of endoscopic assessment are the recognition of BE and the grading of its extent. Other technical assessments, such as barium study or CT, are biased by low sensitivity. Despite several technical improvements, endoscopic evaluation and grading of BE remain difficult and poorly reliable because of inter-observer variability. The first systematic study on the endoscopic recognition of BE was carried out by the International Working Group for the Classification of Oesophagitis (IWGCO), that led to the Prague C \& M Criteria (66) illustrated in Fig. 3. In this classification, the first step for the endoscopic diagnosis of $\mathrm{BE}$ is the correct determination of the position of the anatomical junction between the stomach and the esophagus. Both the maximal length (M) (including tongue) of $\mathrm{BE}$, and the length of circumferential Barrett segment (C) are measured during endoscopy. The diagnosis of BE should be confirmed by random biopsies throughout the length of the suspected regions to identify intestinal metaplasia with goblet cells in samples classically stained with hematoxylin and eosin. Some studies suggest that eight random biopsies should be performed to increase the probability of identifying intestinal metaplasia (11). Histological confirmation varies with the length of columnar epithelium. This classification system has a high degree of overall reliability when the endoscopically visualized segment of $\mathrm{BE}$ is longer than $1 \mathrm{~cm}$.

In 2008, the American College of Gastroenterology Guidelines (Fig. 4) withdrew recommendations for endoscopic screening of patients with GERD. There is no direct evidence supporting endoscopic screening for either BE or AC in individuals with GERD. Recommendations should be individualized for the single patient, and usually screening is considered for patients with chronic long-standing GERD (63). Moreover, no randomized controlled trial has evaluated the efficacy of surveillance, and it is not clear whether surveillance reduces the mortality from esophageal AC. Furthermore, several factors limit the expected benefits of current surveillance strategies, including the low overall incidence of cancer in patients with $\mathrm{BE}$, the absence of a previous diagnosis of $\mathrm{BE}$ in most patients with esophageal $\mathrm{AC}$, and difficulties in the diagnosis of dysplasia because of random biopsy specimens and high variations among pathologists in the interpretation of biopsy findings.

We have already mentioned that in large population-based cohort studies cancer incidence has been shown to be significantly lower $(9,10)$ than $0.5 \%$ per year (11) for non-dysplastic BE. The risk of progression to cancer increases gradually from $1 \%$ 

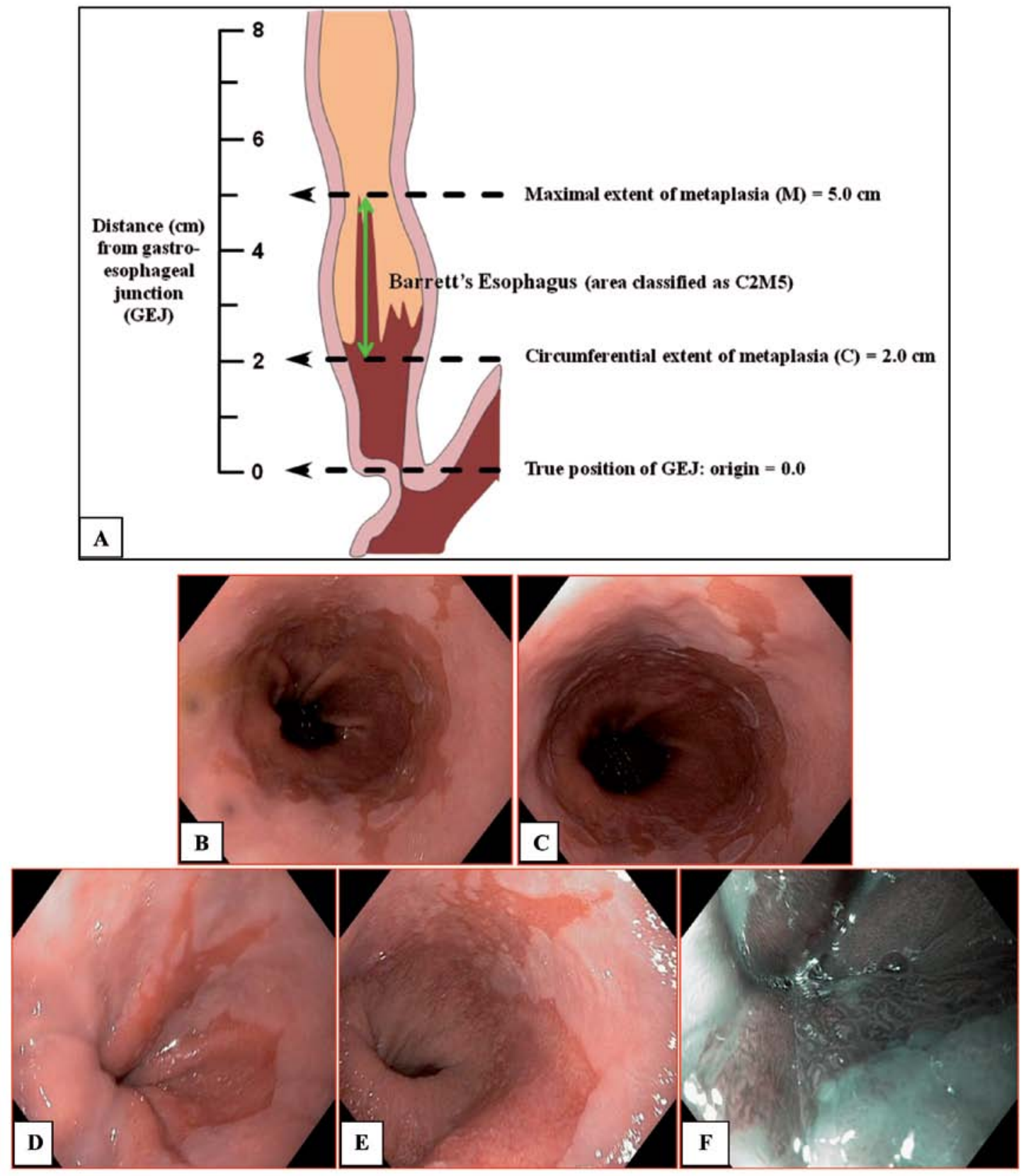

Figure 3. Schematic representation according to Prague criteria and endoscopic images of BE. Panel A, endoscopic detection of BE, showing an area classified as C2M5. Both the maximal length (M) (including tongues) of BE and the length of the circumferential Barrett segment (C) are measured during endoscopy. These numbers can then be used to track the length of the Barrett segment. Panels B and C, endoscopic pictures of BE radiating tongues from the gastro-esophageal junction in a patient previously treated for GERD. Panels D and E, endoscopic white light imaging and magnification $\mathrm{x} 1.5$ of dysplastic $\mathrm{BE}$ from the same patient. Panel F, high resolution endoscopy with Narrow Band Imaging. A clear demarcation line is seen between the mucosa with irregular microvessels and irregular structural pattern, suggestive of dysplasia, and the non-dysplastic BE with regular microvessels and regular microstructural pattern.

to $10 \%$ per year in low-grade dysplasia. The majority of patients with low-grade dysplasia detected on endoscopic surveillance do not have evidence of dysplasia on the subsequent endoscopic examination (67). The surveillance in patients with BE without dysplasia is based on two esophageal examinations with biopsy within 1 year and follow-up with endoscopy every 3 years. In patients with BE with low-grade dysplasia, surveillance consists of two esophageal examinations with biopsy within 1 year and follow-up with endoscopy every year (63).

The risk of developing esophageal $\mathrm{AC}$ rises up to $40 \%$ per year among patients with high-grade dysplasia, with an estimated incidence of 6.6 cases per 100 patients/years (5). In these patients, if mucosal irregularities are detected, a new esophageal examination with biopsy within 3 months is mandatory to exclude the possibility of cancer. Should the pathologist confirm such mucosal irregularity, then strict follow-up and possible endoscopic mucosal resection would be requested. In case of flat mucosa, endoscopic surveillance is intensive (every 3 months) and esophagectomy or ablation should be considered $(63,64)$.

Enhanced imaging techniques have been found to improve the efficiency and accuracy of endoscopic surveillance. Although most of these techniques are not directly comparable with standard endoscopy, preliminary results with the use of narrowband imaging and chromo-endoscopy indicate that they have 


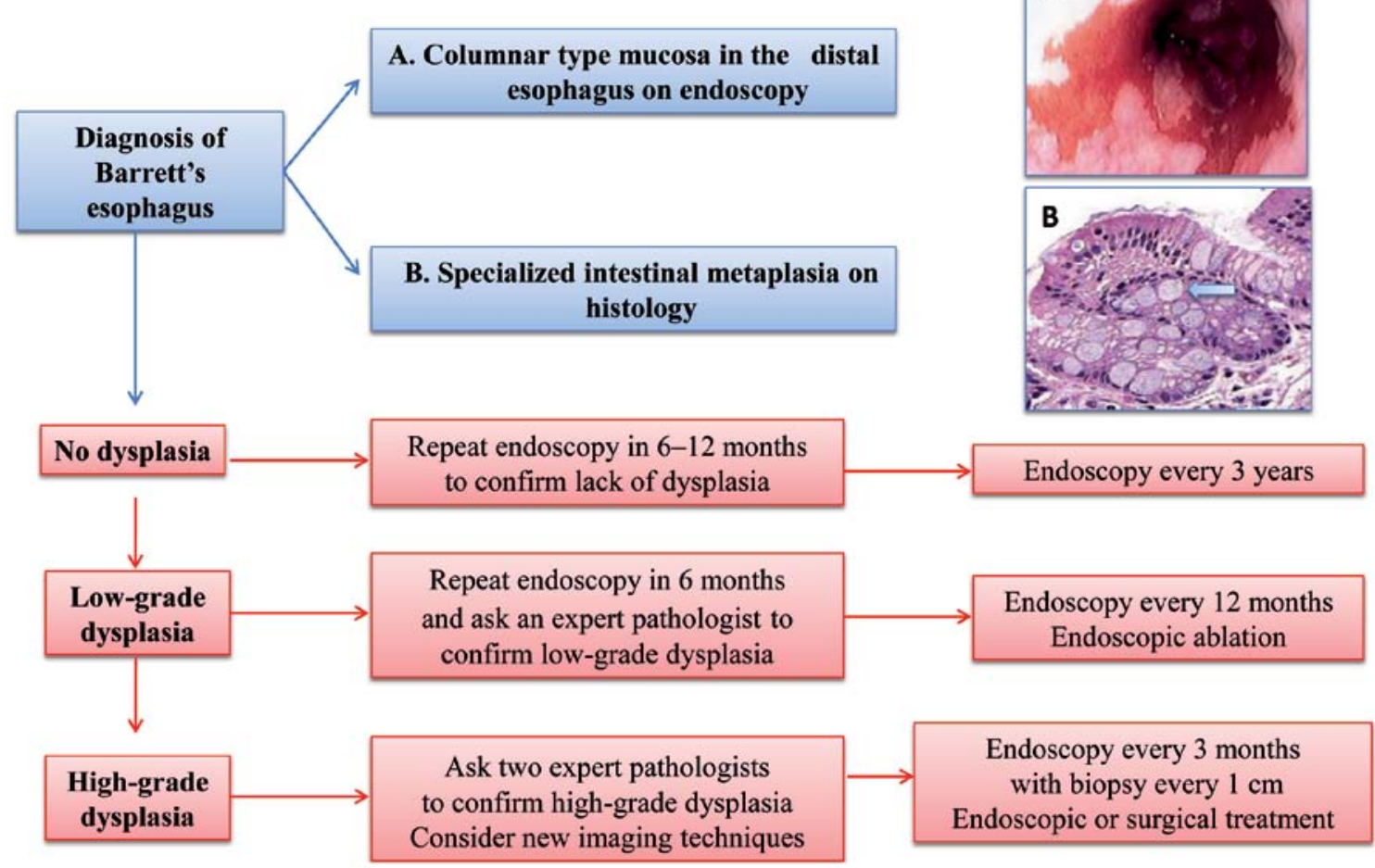

Figure 4. Algorithm for diagnosis, surveillance and management of patients with BE according to the American College of Gastroenterology Guidelines (2008). (A) Endoscopic detection of BE as salmon-coloured mucosal changes in the distal esophagus, characterized by the presence of tongues radiating from the gastroesophageal junction. (B) A biopsy specimen of intestinal metaplasia (arrow points to goblet cell).

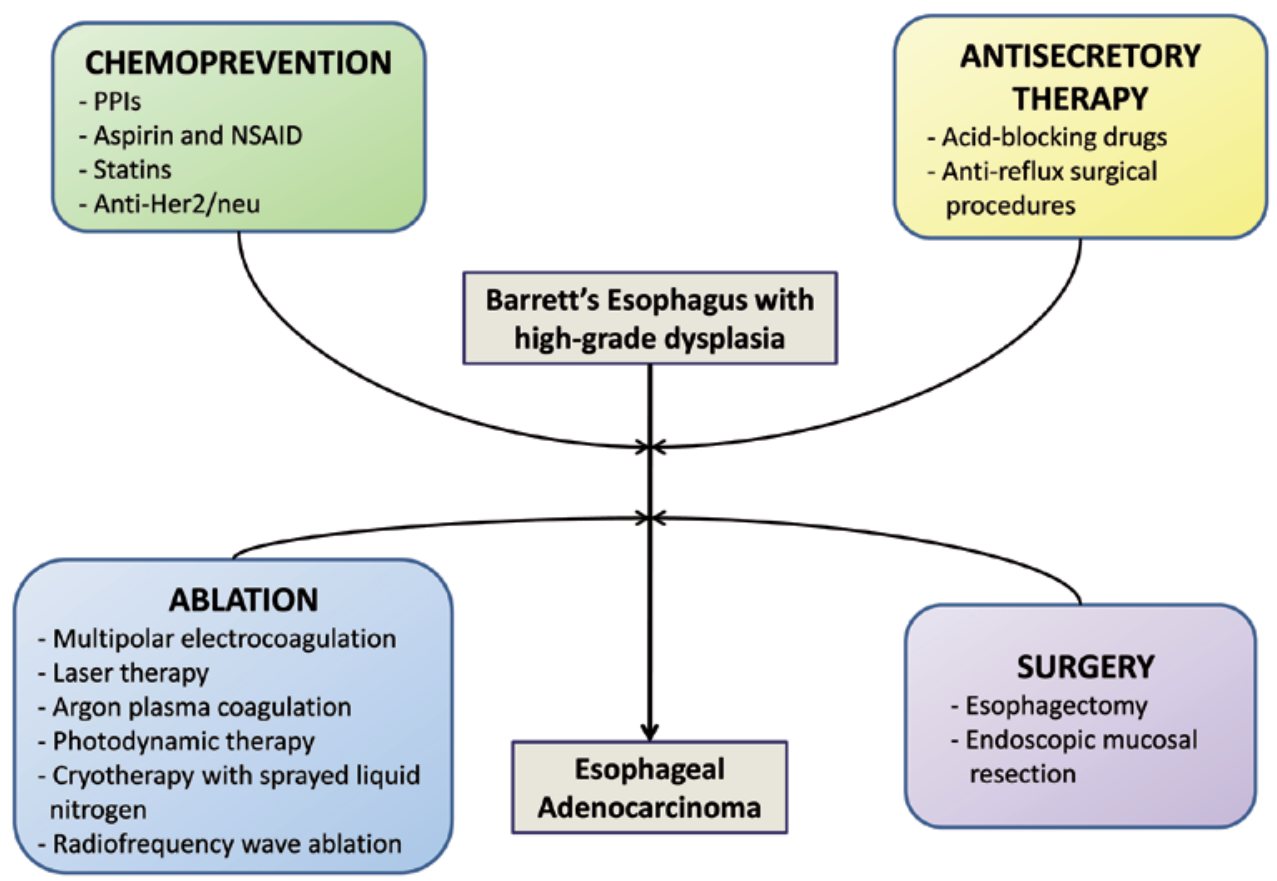

Figure 5. Chemoprevention and therapy in patients with BE and high-grade dysplasia. Possible preventive and therapeutic approaches that can be used in patients with high risk of developing AC. Few and uncontrolled studies have been carried out so far on their efficacy. In particular, comparative evaluations among these procedures are lacking.

a high sensitivity ( 85 to $92 \%$ ) in the diagnosis of neoplasia in patients with BE (68). Narrow-band imaging improves contrast by narrowing the band of white light, filtering it into two major colors (blue and green) which are then better absorbed by blood vessels in the mucosa and submucosa. Combined with highresolution endoscopy, narrow-band imaging produces detailed 
images of the mucosal and vascular surface patterns within the BE segment, and identifies characteristic patterns for nondysplastic intestinal metaplasia, high-grade dysplasia, and early cancer (11). Chromo-endoscopy is a simple technique involving the application of chemical agents to improve the visualization of mucosal surfaces either by selective uptake (vital staining with methylene blue or Lugol's solution) or enhancement of mucosal surface pattern (contrast staining with indigo carmine and acetic acid). Methylene blue is the most common of these stains that colors non-dysplastic SIM in blue, whereas it does not bind to high-grade dysplastic or neoplastic mucosa (69).

\section{Treatment}

As already mentioned, patients with non-dysplastic disease or low-grade dysplasia evolve to high-grade dysplasia or cancer in less than $10 \%$ of cases $(11,18)$, and should therefore undergo periodic endoscopic surveillance without therapy (Fig. 4), according to internationally accepted recommendations $(63,64)$.

On the contrary, patients with high-grade dysplasia, and hence at high risk of malignant transformation, obviously require a more aggressive approach. Esophagectomy should be the standard of care for them (Fig. 5). This approach is based on the results of several studies in which neoplasia was demonstrated in approximately $40 \%$ of resected samples (70). The mortality and morbidity rates of esophagectomy are $3-5 \%$ and $20-50 \%$, respectively, even when performed in largely attended expert centers (71). An alternative surgical approach is endoscopic mucosal resection, that allows for a definite histologic diagnosis and is also potentially curative. This procedure implies the excision of a piece of mucosa of approximately $1.5-2 \mathrm{~cm}$ in diameter (72) and is recommended for lesions confined to the mucosa and to the upper third of the submucosa. It can be used for the definitive treatment of some intra-mucosal cancers arising in BE, or circumferentially by using multiple excisions to remove the whole metaplastic tract. Circumferential resection is followed by esophageal stricture formation in $10-40 \%$ of patients. The risk increases in relation to the number of mucosal resections undertaken. Therefore, endoscopic mucosal excision of the full segment of BE is usually limited to shorter lesions (11). Moreover, it is associated with the risk of neoplastic recurrence in up to $20 \%$ of cases during follow-up (73).

The introduction of new endoscopic treatments characterized by a lower incidence of complications, including the risk of lymphatic or hematogenous dissemination, has reduced the indications of surgery to patients with high grade dysplasia or early AC (74,75). The endoscopic procedures, either by resection or by ablation of the inner lining of the esophagus, usually result in regenerated squamous epithelium. Although the malignant potential of regenerating epithelium has not been fully assessed, this reversion seems to result in a substantially decreased risk of esophageal AC. Endoscopic ablation techniques include photodynamic therapy, multipolar electrocoagulation, laser therapy, argon plasma coagulation, cryotherapy with sprayed liquid nitrogen and radiofrequency wave ablation (11) (Fig. 5). Because comparative studies among these techniques are not available so far, their choice is mostly empirical and largely dependent on the patient's characteristics and preferences, as well as on the expertise of the operator.
Photodynamic therapy has been extensively investigated. It involves the administration of a photosensitizer substrate which accumulates in the tumor tissue and is subsequently activated by a laser impulse endoscopically applied to the malignant site. This results in the formation of free oxygen radicals in the tumor tissue, leading to ischemic necrosis of the tumor cells. The strongest evidence for the effectiveness of photodynamic therapy derives from a prospective, randomized study in which, after a five years' follow-up, a significant difference was shown between a group of patients treated with photodynamic therapy plus omeprazole vs. a group treated with omeprazole alone. In this study, the percentage of ablation in high grade dysplasia was $77 \%$ vs. $39 \%(\mathrm{p}=0.004)$, whereas the recurrence of neoplasia was $15 \%$ vs. $29 \%$ ( $p=0.027$ ) (75). The occurrence of esophageal stenosis is a relatively frequent adverse event of photodynamic therapy (27-34\% of cases), which typically develops within one month (76).

Radiofrequency ablation is also used to treat BE. It consists of a high-power radiofrequency energy generator, sizing balloon and ablation catheters. In patients with dysplastic BE, radiofrequency ablation is associated with a high rate of complete eradication of both dysplasia and intestinal metaplasia, and a reduced risk of disease progression (77). When circumferential radiofrequency ablation was applied to patients with $\mathrm{BE}$ without dysplasia, its complete elimination occurred in $70 \%$ of cases assessed after 1 year follow-up and there were no subsequent strictures or buried glands (78,79).

Since acid reflux is thought to play an important role in the development of esophageal intestinal metaplasia, most treatment strategies focus on acid-blocking drugs or anti-reflux surgical procedures, though no prospective trials are available showing that controlling reflux symptoms and even esophagitis can indeed result in the prevention of esophageal AC. The association between the use of proton pump inhibitors (PPIs) and the risk of esophageal AC has been examined in observational studies, but controversial results have been achieved $(80,81)$. For example, a retrospective cohort study evaluated the use of PPIs in 344 individuals without any dysplasia at baseline endoscopy. No association with the development of dysplasia was reported; on the contrary, a statistically significant reduction in the risk of high-grade dysplasia and/or esophageal AC was observed (82).

Several studies have considered aspirin and NSAID as chemopreventive drugs. Their use is associated with a $50 \%$ reduced risk of developing esophageal AC (83). A large European study (84) aimed at defining the role of low-dose aspirin and PPIs, alone or in combination, seems to delineate a potential role for these drugs and their dosing in the chemoprevention of esophageal AC. On the basis of emerging evidence showing increased COX2 levels in BE (55), COX2 inhibitors have also been reported to decrease the incidence of esophageal $\mathrm{AC}$ in $\mathrm{BE}$, although conflicting data have been published on their role as chemopreventive drugs and on the optimum dose of these drugs (85). Statins are not significantly associated with the risk of neoplasia in patients with BE (82) and, in addition to NSAIDs and PPIs, they can even exert (86) a chemopreventive effect in esophageal AC.

The complexity of the process involved in neoplastic progression suggests that no single therapeutic measure is likely to be sufficient in clinical practice. The best strategy of care for patients with BE needs further elucidation. Currently, a risk 
stratification is needed. Given the overall low risk of neoplastic progression of $\mathrm{BE}$, there is an obvious interest to search for biomarkers that might identify people at particular cancer risk. Among biomarkers predictive of neoplastic progression, abnormalities in the tumor-suppressor genes CDKN2A (which encodes the cyclin-dependent kinase inhibitor p16INK4a) and TP53 (which encodes tumor protein p53), and the presence of tetraploidy or aneuploidy in epithelial cells should be mentioned (87). Tailored risk stratification, based on interactions among environmental and genetic factors, is essential to deliver personalized care to patients with high risk of developing esophageal AC.

\section{Acknowledgements}

This study was supported in part by grants from the Italian Association for Cancer Research (AIRC, Milan, Italy), the Italian Foundation 'Cassa di Risparmio di Puglia' (Bari, Italy), and the strategic project 'BIOTECNOTER' of the Apulia Region (Bari, Italy).

\section{References}

1. Enzinger P and Mayer R: Esophageal cancer. N Engl J Med 349 2241-2252, 2003.

2. Ajani JA, Barthel JS, Bentrem DJ, et al: Esophageal and esophago-gastric junction cancers. J Natl Compr Canc Netw 9: 830-887, 2011

3. Jemal A, Bray F, Center MM, Ferlay J, Ward E and Forman D: Global cancer statistics. CA Cancer J Clin 61: 69-90, 2011.

4. Parkin DM: International variation. Oncogene 23: 6329-6340, 2004.

5. Pohl H and Welch HG: The role of overdiagnosis and reclassification in the marked increase of esophageal adenocarcinoma incidence. J Natl Cancer Inst 97: 142-146, 2005.

6. Sharma P: Clinical practice. Barrett's esophagus. N Engl J Med 361: 2548-2556, 2009.

7. Ronkainen J, Aro P, Storskrubb T, et al: Prevalence of Barrett's esophagus in the general population: an endoscopic study. Gastroenterology 129: 1825-1831, 2005.

8. Zou D, He J, Ma X, et al: Helicobacter pylori infection and gastritis: the systematic investigation of gastrointestinal diseases in China (SILC). J Gastroenterol Hepatol 26: 908-915, 2011.

9. Bhat S, Coleman HG, Yousef F, Johnston BT, McManus DT, Gavin AT and Murray LJ: Risk of malignant progression in Barrett's esophagus patients: results from a large populationbased study. J Natl Cancer Inst 103: 1049-1057, 2011.

10. Hvid-Jensen F, Pedersen L, Drewes AM, Sørensen HT and Funch-Jensen P: Incidence of adenocarcinoma among patients with Barrett's esophagus. N Engl J Med 365: 1375-1383, 2011.

11. Shaheen NJ and Richter JE: Barrett's esophagus. Lancet 373 : 850-861, 2009

12. Kahrilas PJ: The problems with surveillance of Barrett's esophagus. N Engl J Med 365: 1437-1438, 2011.

13. Garud SS, Keilin S, Cai Q and Willingham FF: Diagnosis and management of Barrett's esophagus for the endoscopist. Ther Adv Gastroenterol 3: 227-238, 2010.

14. Dent J, El-Serag HB, Wallander MA and Johansson S: Epidemiology of gastro-oesophageal reflux disease: a systematic review. Gut 54: 710-717, 2005.

15. Whiteman DC, Parmar P, Fahey P, et al: Association of Helicobacter pylori infection with reduced risk for esophageal cancer is independent of environmental and genetic modifiers. Gastroenterol 139: 73-83, 2010.

16. Barrett NR: Chronic peptic ulcer of the oesophagus and 'oesophagitis'. Br J Surg 38: 175-182, 1950.

17. Allison PR and Johnstone AS: The oesophagus lined with gastric mucous membrane. Thorax 8: 87-101, 1953.

18. Naef AP, Savary M and Ozzello L: Columnar-lined lower esophagus: an acquired lesion with malignant predisposition Report on 140 cases of Barrett's esophagus with 12 adenocarcinomas. J Thorac Cardiovasc Surg 70: 826-835, 1975.
19. Hamilton SR and Aaltonen LA: World Health Organization of Tumours Classification. Pathology and Genetics of Tumours of the Digestive System. IARC Press, Lyon, 2000

20. Schlemper RJ, Riddell RH, Kato Y, et al: The Vienna classification of gastrointestinal epithelial neoplasia. Gut 47: 251-255, 2000.

21. Lagergren J: Influence of obesity on the risk of esophageal disorders. Nat Rev Gastroenterol Hepatol 8: 340-347, 2011.

22. McElholm AR, McKnight AJ, Patterson CC, Johnston BT, Hardie LJ and Murray LJ: A population-based study of IGF axis polymorphisms and the esophageal inflammation, metaplasia, adenocarcinoma sequence. Gastroenterology 139: 204-212, 2010.

23. Kendall BJ, Macdonald GA, Hayward NK, et al: Leptin and the risk of Barrett's oesophagus. Gut 57: 448-454, 2008.

24. Rubenstein JH, Kao JY, Madanick RD, et al: Association of adiponectin multimers with Barrett's oesophagus. Gut 58: 1583-1589, 2009

25. Fletcher J, Wirz A, Henry E and McKoll KE: Studies of acid exposure immediately above the gastro-oesophageal squamocolumnar junction: evidence of short segment reflux. Gut 53: 168-173, 2004.

26. Farrè R, De Vos R, Geboes K, et al: Critical role of stress in increased oesophageal mucosa permeability and dilated intercellular spaces. Gut 56: 1191-1197, 2007.

27. Jovov B, Van Itallie CM, Shaheen NJ, Carson JL, Gambling TM, Anderson JM and Orlando RC: Claudin-18: a dominant tight junction protein in Barrett's esophagus and likely contributor to its acid resistance. Am J Physiol Gastrointest Liver Physiol 293: 1106-1113, 2007.

28. Clemons NJ, McColl KE and Fitzgerald RC: Nitric oxide and acid induce double-strand DNA breaks in Barrett's esophagus carcinogenesis via distinct mechanisms. Gastroenterology 133: 1198-1209, 2007.

29. Dvorak K, Payne CM, Chavarria M, et al: Bile acids in combination with low $\mathrm{pH}$ induce oxidative stress and oxidative DNA damage: relevance to the pathogenesis of Barrett's oesophagus. Gut 56: 763-771, 2007.

30. Sun X, Elston R, Barnholtz-Sloan J, et al: A segregation analysis of Barrett's esophagus and associated adenocarcinomas. Cancer Epidemiol Biomarkers Prev 19: 666-674, 2010.

31. Chak A, Ochs-Balcom H, Falk G, et al: Familiality in Barrett's esophagus, adenocarcinoma of the esophagus, and adenocarcinoma of the gastroesophageal junction. Cancer Epidemiol Biomarkers Prev 15: 1668-1673, 2006.

32. Croagh D, Phillips WA, Redvers R, Thomas RJ and Kaur P: Identification of candidate murine esophageal stem cells using a combination of cell kinetic studies and cell surface markers. Stem Cells 25: 313-318, 2007.

33. Croagh D, Thomas RJ, Phillips WA and Kaur P: Esophageal stem cells - a review of their identification and characterization. Stem Cell Rev 4: 261-268, 2008.

34. Leedham SJ, Preston SL, McDonald SA, et al: Individual crypt genetic heterogeneity and the origin of metaplastic glandular epithelium in human Barrett's oesophagus. Gut 57: 1041-1408, 2008.

35. Sarosi G, Brown G, Jaiswal K, et al: Bone marrow progenitor cells contribute to esophageal regeneration and metaplasia in a rat model of Barrett's esophagus. Dis Esophagus 21: 43-50, 2008.

36. Yu WY, Slack JM and Tosh D: Conversion of columnar to stratified squamous epithelium in the developing mouse oesophagus. Dev Biol 284: 157-170, 2005.

37. Kong J, Crissey MA, Funakoshi S, Kreindler JL and Lynch JP: Ectopic $\mathrm{Cdx} 2$ expression in murine esophagus models an intermediate stage in the emergence of Barrett's esophagus. PloS One 6: e18280, 2011.

38. Kosinski C, Stange DE, Xu C, et al: Indian hedgehog regulates intestinal stem cell fate through epithelial-mesenchymal interactions during development. Gastroenterology 139: 893-903, 2010.

39. Kazumori H, Ishihara S and Kinoshita Y: Roles of caudalrelated homeobox gene $\mathrm{Cdx} 1$ in oesophageal epithelial cells in Barrett's epithelium development. Gut 58: 620-628, 2009.

40. Phillips WA, Lord RV, Nancarrow DJ, Watson DJ and Whiteman DC: Barrett's esophagus. J Gastroenterol Hepatol 26: 639-648, 2011

41. Colleypriest BJ, Farrant JM, Slack JM and Tosh D: The role of Cdx2 in Barrett's metaplasia. Biochem Soc Trans 38: 364-369, 2010. 
42. Mutoh H, Sakurai S, Satoh K, Osaka H, Hakamata Y, Takeuchi T and Sugano K: Cdx1 induced intestinal metaplasia in the transgenic mouse stomach: comparative study with $\mathrm{Cdx} 2$ transgenic mice. Gut 53: 1416-1423, 2010.

43. Barros R, da Costa LT, Pinto-de-Sousa J, Duluc I, Freund JN, David L and Almeida R: CDX2 autoregulation in human intestinal metaplasia of the stomach: impact on the stability of the phenotype. Gut 60: 290-298, 2011.

44. Huo X, Zhang HY, Zhang XI, et al: Acid and bile salt-induced CDX2 expression differs in esophageal squamous cells from patients with and without Barrett's esophagus. Gastroenterology 139: 194-203, 2010.

45. Chen X, Qin R, Liu B, Ma Y, et al: Multilayered epithelium in a rat model and human Barrett's esophagus: similar expression patterns of transcription factors and differentiation markers. BMC Gastroenterol 8: 1-9, 2008.

46. Badreddine RJ and Wang KK: Barrett esophagus: an update Nat Rev Gastroenterol Hepatol 7: 369-378, 2010.

47. Wang DH, Clemons NJ, Miyashita T, et al: Aberrant epithelialmesenchymal Hedgehog signaling characterizes Barrett's metaplasia. Gastroenterology 138: 1810-1822, 2010.

48. Liu W, Hahn H, Odze RD and Goyal RK: Metaplastic esophageal columnar epithelium without goblet cells shows DNA content abnormalities similar to goblet cell-containing epithelium. Am J Gastroenterol 104: 816-824, 2009.

49. Chaves P, Crespo M, Ribeiro C, et al: Chromosomal analysis of Barrett's cells: demonstration of instability and detection of the metaplastic lineage involved. Mod Pathol 20: 788-796, 2007.

50. Li X, Galipeau PC, Sanchez CA, et al: Single nucleotide polymorphism-based genome-wide chromosome copy change, loss of heterozygosity, and aneuploidy in Barrett's esophagus neoplastic progression. Cancer Prev Res 1: 413-423, 2008

51. Wu IC, Zhao Y, Zhai R, et al: Association between polymorphisms in cancer-related genes and early onset of esophageal adenocarcinoma. Neoplasia 13: 386-392, 2011.

52. Galipeau PC, Li X, Blount PL, et al: NSAIDs modulate CDKN2A, TP53, and DNA content risk for progression to esophageal adenocarcinoma. PLoS Med 4: e67, 2007.

53. Xing J, Ajani JA, Chen M, et al: Constitutive short telomere length of chromosome $17 p$ and $12 q$ but not $11 q$ and $2 p$ is associated with an increased risk for esophageal cancer. Cancer Prev Res 2: 459-465, 2009.

54. Wang C, Yuan Y and Hunt RH: Helicobacter pylori infection and Barrett's esophagus: a systematic review and meta-analysis. Am J Gastroenterol 104: 492-500, 2009.

55. Anderson LA, Johnston BT, Watson RG, et al: Nonsteroidal anti-inflammatory drugs and the esophageal inflammationmetaplasia-adenocarcinoma sequence. Cancer Res 66: 4975-4982, 2006

56. Kubo A, Block G, Quesenberry CP, Buffler P and Corley DA: Effects of dietary fiber, fats, and meat intakes on the risk of Barrett's esophagus. Nutr Cancer 61: 607-616, 2009.

57. Kubo A, Levin TR, Block G, et al: Dietary antioxidants, fruits, and vegetables and the risk of Barrett's esophagus. Am J Gastroenterol 103: 1614-1623, 2008.

58. Rossi E, Grisanti S, Villanacci V, et al: HER-2 overexpression/ amplification in Barrett's oesophagus predicts early transition from dysplasia to adenocarcinoma: a clinico-pathologic study. J Cell Mol Med 13: 3826-3833, 2009.

59. Vakil N, van Zanten SV, Kahrilas P, Dent J and Jones R: The Montreal definition and classification of gastroesophageal reflux disease: a global evidence-based consensus. Am J Gastroenterol 101: 1900-1920, 2006

60. Lundell LR, Dent J, Bennett JR, et al: Endoscopic assessment of oesophagitis: clinical and functional correlates and further validation of the Los Angeles classification. Gut 45: 172-180, 1999.

61. American Gastroenterological Association, Spechler SJ, Sharma P, Souza RF, Inadomi JM and Shaheen NJ: American Gastroenterological Association medical position statement on the management of Barrett's esophagus. Gastroenterology 140 1084-1091, 2011.

62. Voltaggio L, Montgomery EA and Lam-Himlin D: A clinical and histopathologic focus on Barrett esophagus and Barrettrelated dysplasia. Arch Pathol Lab Med 135: 1249-1260, 2011.

63. Wang KK, Sampliner RE and Practice Parameters Committee of the American College of Gastroenterology: Updated guidelines 2008 for the diagnosis, surveillance and therapy of Barrett's esophagus. Am J Gastroenterol 103: 788-797, 2008.

64. Playford RJ: New British Society of Gastroenterology (BSG) guidelines for the diagnosis and management of Barrett's oesophagus. Gut 55: 442, 2006.
65. Sikkema M, Looman CWN, Steyerberg EW, et al: Predictors for neoplastic progression in patients with Barrett's esophagus: a prospective cohort study. Am J Gastroenterol 106: 1231-1238, 2011.

66. Sharma P, Dent J, Armstrong D, et al: The development and validation of an endoscopic grading system for Barrett's esophagus: the Prague C \& M Criteria. Gastroenterology 131: 1392-1399, 2006.

67. Wani S, Mathur S and Sharma P: How to manage a Barrett's esophagus patient with low-grade dysplasia. Clin Gastroenterol Hepatol 7: 27-32, 2009.

68. Mannath J, Subramanian V, Hawkey CJ and Raqunath K: Narrow band imaging for characterization of high grade dysplasia and specialized intestinal metaplasia in Barrett's esophagus: a meta-analysis. Endoscopy 42: 351-359, 2010.

69. Wasielica-Berger J, Baniukiewicz A, Wroblewski E, Chwiesko A and Dabrowski A: Magnification endoscopy and chromoendoscopy in evaluation of specialized intestinal metaplasia in Barrett's esophagus. Dig Dis Sci 56: 1987-1995, 2011.

70. Prasad GA, Wu TT, Wigle DA, et al: Endoscopic and surgical treatment of mucosal (T1a) esophageal adenocarcinoma in Barrett's esophagus. Gastroenterology 137: 815-823, 2009.

71. Yachimski P, Nishioka NS, Richards E and Hur C: Treatment of Barrett's esophagus with high-grade dysplasia or cancer: predictor of surgical versus endoscopic therapy. Clin Gastroenterol Hepatol 6: 1206-1211, 2008.

72. Fleischer DE, Overholt BF, Sharma P, et al: Endoscopic ablation of Barrett's esophagus: a multicenter study with 2.5-year follow-up. Gastrointest Endosc 68: 867-876, 2008.

73. Pech O, Behrens A, May A, et al: Long-term results and risk factor analysis for recurrence after curative endoscopic therapy in 349 patients with high-grade intraepithelial neoplasia and mucosal adenocarcinoma in Barrett's oesophagus. Gut 57: 1200-1206, 2008.

74. Gaddam S and Sharma P: Advances in endoscopic diagnosis and treatment of Barrett's esophagus. J Dig Dis 11: 323-333, 2010.

75. Nealis TB, Washington K and Keswani RN: Endoscopic therapy of esophageal premalignancy and early malignancy. J Natl Compr Cancer Netw 9: 890-899, 2011

76. Yachimski P, Puricelli WP and Nishioka NS: Patient predictors of esophageal stricture development after photodynamic therapy. Clin Gastroenterol Hepatol 6: 302-308, 2008.

77. Ulsiewicz WJ and Shaheen NJ: The role of radiofrequency ablation in the management of Barrett's esophagus. Gastrointest Endosc Clin N Am 21: 95-109, 2011.

78. Shaheen NJ, Overholt BF, Sampliner RE, et al: Durability of radiofrequency ablation in Barrett's esophagus with dysplasia. Gastroenterology 141: 460-468, 2011.

79. Shaheen NJ, Sharma P, Overholt BF, et al: Radiofrequency ablation in Barrett's esophagus with dysplasia. N Engl J Med 360: 2277-2288, 2009.

80. Dent J: Barrett's esophagus: A historical perspective, an update on core practicalities and predictions on future evolutions of management. J Gastroenterol Hepatol 26: 11-30, 2011.

81. El-Serag HB, Aguirre TV, Davis S, Kuebeler M, Bhattacharyya A and Sampliner RE: Proton pump inhibitors are associated with reduced incidence of dysplasia in Barrett's esophagus. Am J Gastroenterol 99: 1877-1883, 2004

82. Nguyen DM, El-Serag HB, Henderson L, Stein D, Bhattacharyya A and Sampliner RE: Medication usage and the risk of neoplasia in patients with Barrett's esophagus. Clin Gastroenterol Hepatol 7: 1299-1304, 2009.

83. Jankowski JA and Hooper PA: Chemoprevention in Barrett's esophagus: A pill a day? Gastrointest Endosc Clin N Am 21: $155-170,2011$.

84. Neumann H, Mönkemüller K, Vieth $\mathrm{M}$ and Malfertheiner P. Chemoprevention of adenocarcinoma associated with Barrett's esophagus: potential options. Dig Dis 27: 18-23, 2009.

85. Heath EI, Canto MI, Piantadosi S, et al: Secondary chemoprevention of Barrett's esophagus with celecoxib: results of a randomized trial. J Natl Cancer Inst 99: 545-557, 2007.

86. Das D, Chilton AP and Jankowski JA: Chemoprevention of oesophageal cancer and the AspECT trial. Recent Results Cancer Res 181: 161-169, 2009.

87. Ong CA, Lao-Sirieix P and Fitzgerald RC: Biomarkers in Barrett's esophagus and esophageal adenocarcinoma: Predictors of progression and prognosis. World J Gastroenterol 16: $5669-5681,2010$ 